\title{
Preparation and characterization of polymeric dispersants based on vegetable oils for
} printing ink application

\author{
Nadia A.Yossif ${ }^{1}$, Nadia G. Kandile ${ }^{1}$ ، Nabel A. Negm ${ }^{2}$, Mohamed A. Abdelaziz ${ }^{3}$ \\ ${ }^{1}$ Chemistry Department, Faculty of women, Ainshams University, Cairo, Egypt \\ ${ }^{2}$ Petrochemicals Department, Egyptian petroleum research institute, Cairo, Egypt \\ ${ }^{3}$ R\&D Department, Degla chemicals, Cairo, Egypt
}

\begin{abstract}
In this work, a novel vegetable oil-based polymers were prepared by epoxidation of soybean oil (SBO) and castor oil (CO) followed by ring opening reaction of epoxidized oil with polyether amine and poly propylene glycol. The prepared polymers were characterized by FTIR and GPC. The properties of vegetable oils and epoxidized vegetable oil (EVO) were studied. The prepared polymers were employed as novel polymeric dispersants for pigment dispersion in solvent based printing ink application. The mechanical and optical properties of prepared ink were studied. The net technical properties of the new ink formulations are relatively comparable to the prepared printing ink from standard polymeric dispersant. The polymeric dispersant 2 (PD2) and polymeric dispersant 4 (PD4) gave the best optical and mechanical properties among the prepared polymers.
\end{abstract}

Keywords: Vegetable oils, Printing inks, Polymeric dispersants, Pigment, Castor oil.

\section{Introduction}

The manufacture of printing ink is a technologically advanced, highly specialized and complex process [Pal L and Fleming P (2006)]. Preparation of stable, homogeneous and fine dispersion of pigment is not facile because its prone to aggregate. The dispersion of pigment strongly affect the optical properties such as color strength, transparency, gloss and mechanical properties such as adhesion of printed ink film [Nsib F et al (2006); Kuo K et al (2008); Tryznowska ZZ (2016)]. Stabilization of pigment dispersion usually results from adsorption of dispersing agent molecules from solution onto the particle surface of the pigment creating repulsive forces between the particle in suspension either through electrostatic repulsion or from steric prevention of coagulation.

Corresponding Author: Mohamed A.Abdelaziz (Email:zezo_maaan1@yahoo.com) 
The degree of dispersion of a particle suspension may be defined as the extent to which the individual powder particles become separated from one another in the liquid medium [Reuter E et al (1999); Nsib F et al (2006); Wang J et al (2006);].

Polymeric pigment dispersants are copolymers with pigment affinic "anchoring groups" and soluble polymeric chains [Schofield JD and Calbo LJ (1992); Spinelli HJ (1998)]. The polymeric dispersants are used to obtain homogeneous dispersion of the pigment in the liquid phase that leads to weak viscosity and allows high pigment loading and high tinting strength [Clarke JB (1997); Schofield JD (2002); Lokhande GP and Jagtap RN (2016)].

Health-related issues, stringent environmental protection policies, search for costeffective and alternative materials and the quest for renewability, sustainability and highperformance materials for technical applications have led to intense research in the production of renewable polymers from plant seed oils and shift in focus from the petrochemical based polymers [Salih $N$ et al (2011); Saithai P et al (2013); Adekunle KF (2015)]. Vegetable oils are a part of large family of chemical compounds known as fats or lipids which are made up predominantly of triesters of glycerol with fatty acids which can be processed into high value oleochemicals for various industries [Abdullah BM and Salimon J (2010)]. The general structure of vegetable oils is shown in Figure 1 which is triglycerides comprise three fatty acids joined by a glycerol center [Sudha GS et al (2015)].

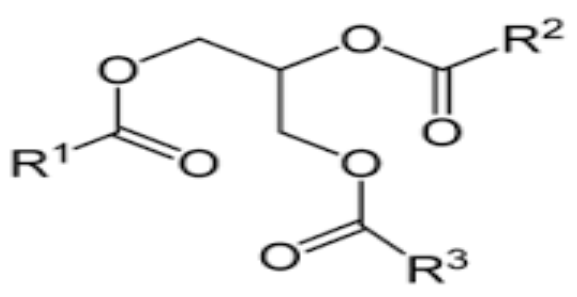

Figure. 1 Triglyceride chain containing three fatty acids by a glycerol center.

The fatty acids of vegetable oils may be saturated and unsaturated fatty acids. Castor oil, cottonseed oil, linseed oil, jatropha oil, rapeseed oil and soybean oil are examples on vegetable oils [Vlček T and Petrović ZS (2006); Sudha GS et al (2015)]. The unsaturation present (double bond) in vegetable oils can be chemically modified to form epoxidized vegetable oils [Vlček T and Petrović ZS (2006); Zhan G et al (2008); Balo F (2011)]. Epoxidation of double bond has been studied in many papers [Meyer $\mathbf{P}$ et al (2008); Milchert E et al (2010); Mohammad M et al (2011); Saremi K et al (2012); Mushtaq M et al (2013)]. Epoxidation is generally performed using organic peracids formed in situ via the attack of $\mathrm{H}_{2} \mathrm{O}_{2}$ on a carboxylic acid in aqueous solution [Milchert $\mathbf{E}$ et al (2010)]. Due to the high reactivity of the oxirane ring, epoxides can also be used for the synthesis of 
chemicals like olefinic, carbonyl compounds, alcohols, alkanolamines, glycols and polymers like polyurethanes, epoxy resin, polyesters [Dinda $S$ et al (2008); Mohammad $M$ et al (2011); Mushtaq M et al (2013)]. Castor oil, soybean oil are the target of this work. Castor oil is obtained from the seeds of the castor oil plant Ricinus. It consists of about $90 \%$ ricinoleic acid (12-hydroxy cis-9-octadecenoic acid), due to its unique structure, having fatty acids with many hydroxyl groups, makes it a very useful for industrial purpose like cosmetics, paints, adhesives, plastics, rubbers, and pharmaceuticals [Can E et al (2006); Kim HM et al (2010); Alaa MA et al (2014)].

Soybean oil is one of the most studied oils because of its ecofriendly nature and cost effectiveness. In soybean oil the major fatty acid is linoleic acid. Thus it was greatly utilized in versatile industrial fields including: coatings, printing inks, adhesives, lubricants and plastics [Eren T et al (2003); Eren T and Küsefoğlu SH (2004); Zhu J et al (2004); Holser RA (2008); Takahashi T et al (2008); Biswas A et al (2008); Lubguban AA et al (2009); Liu W et al (2016);]. Figures 2-3 represent the structures of castor oil and soybean oil, respectively.

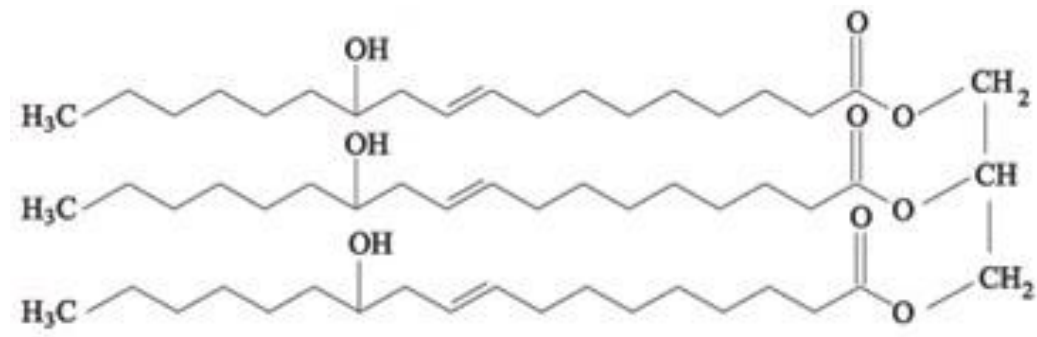

Figure. 2 Major triglyceride of castor oil.

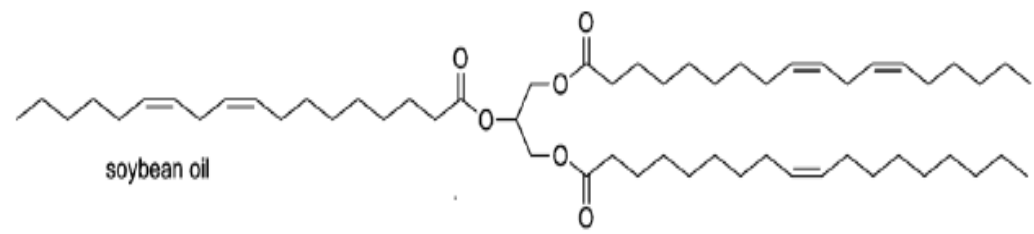

Figure. 3 Major triglyceride of soybean oil.

Among the various reactions of oxiranes aminolysis is a classical route to $\beta$-amino alcohols formation, an important class of compounds with pharmaceutical and biological properties [Aug $\mathbf{J}$ and Leroy $\mathbf{F}$ (1996)]. Many compounds were prepared by the aminolysis of epoxides with amines under basic or acidic catalysts in organic solvents [Curini $\mathbf{M}$ et al (2001); Philippe C et al (2009); Stropoli SJ and Elrod MJ (2015)]. In the present study, we report the synthesis of ecofriendly polymeric dispersant for pigmented ink application by 
epoxidation of soybean oil, castor oil followed by ring opening using polyether amine and polypropylene glycol.

\section{Materials and Methods}

\subsection{Materials}

Chemicals were obtained as follows: polyether amine Jeffamine M-2005 (MW= 2000 g/mol) (Huntsman-Belgium), polypropylene glycol (Invista Specialty Chemicals), castor oil (CO) and commercial cooking-grade soybean oil (SBO) (a local market), ethyl acetate and methanol (Petrochem-KSA), hydrogen peroxide 50\% (Piochem), zinc chloride, magnesium sulfate and $p$-toluene sulfonic acid (Oxford), formic acid, acetic acid, sodium chloride, sodium carbonate (ADWIC-Egypt).

\subsection{Preparation of polymeric Dispersants}

\subsubsection{Epoxidation of vegetable oil}

Vegetable oils and acetic acid (in case of castor oil) or formic acid (in case of soybean oil) were mixed in a round bottom flask and stirred at $550 \mathrm{rpm}$ under controlled temperature in a water bath with a temperature of $50 \pm 2{ }^{\circ} \mathrm{C}$. To start the epoxidation, hydrogen peroxide solution (50\%) was added drop wisely into the mixture during the first $2 \mathrm{~h}$ of the reaction. The molar ratio of carbon double bonds to hydrogen peroxide $\left(\mathrm{C}=\mathrm{C}: \mathrm{H}_{2} \mathrm{O}_{2}\right)$ was 1 :1.7. After charging $\mathrm{H}_{2} \mathrm{O}_{2}$ was completed, the reaction continued under mixing and controlling the temperature at $50{ }^{\circ} \mathrm{C}$ for a further $5 \mathrm{~h}$ then the mixture was cooled to room temperature. To purify the epoxidized oil, it was poured into a separating funnel and the oil layer was washed successively with 5\% sodium carbonate solution and 5\% sodium chloride solution, respectively. Ethyl acetate was used to enhance the separation of the oil product from water phase. The water and solvent were then distilled off under a rotary vacuum evaporator. The oil phase was further dried above anhydrous magnesium sulfate and then filtered. Epoxidation reaction is represented in Figure 4.

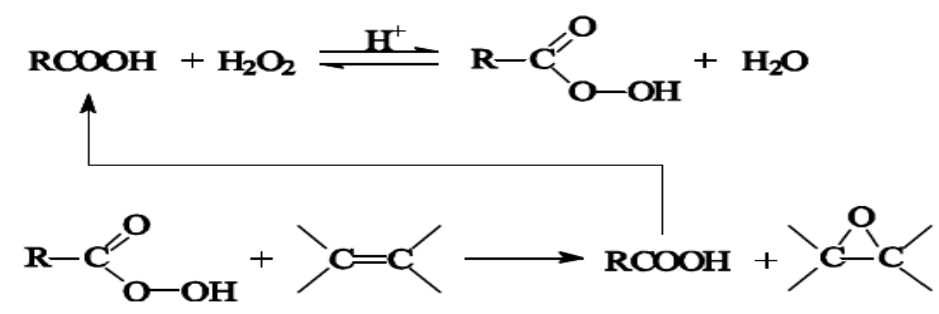

Figure 4: Reactions of epoxidation of oils with peracid formed in situ.

A series of polymeric dispersants were prepared based on two different types of epoxidized vegetable oils (Epoxidized soybean oil, Epoxidized castor oil) by conventional 
epoxidation method followed by ring opening using polyether amine and polypropylene glycol.

\subsubsection{Preparation of polymeric dispersant 1 (PD1)}

PD1 was prepared by ring opening of epoxidized soybean oil in which epoxidized oil was mixed with methanol in presence of $p$-toluene sulfonic acid as a catalyst and ethyl acetate as a solvent at $50^{\circ} \mathrm{C}$ for partially ring opening of epoxidized oil. The partially ring opened epoxidized oil was cool down, Jeffamine M-2005 was added and the temperature was raised to $75-80^{\circ} \mathrm{C}$ in presence of $\mathrm{ZnCl}_{2}$ as a catalyst. The reaction mixture was left for $4 \mathrm{~h}$ then cooled to room temperature. The prepared polymer was purified by filtration of solid catalyst. The excess ethyl acetate was distilled by vacuum distillation to obtain product of approximately $100 \%$ solid content.

\subsubsection{Preparation of polymeric dispersant 2 (PD2)}

PD2 was prepared using the previous method for preparation of PD1, but using jeffamine only for the ring opening of the epoxidized soybean oil.

\subsubsection{Preparation of polymeric dispersant 3 (PD3)}

PD3 was prepared by ring opening method of epoxidized soybean oil using polypropylene glycol where epoxidized soybean oil and polypropylene glycol were mixed in round bottom flask in the presence of $p$-toluene sulfonic acid as a catalyst and at temperature of $110^{\circ} \mathrm{C}$ for $8 \mathrm{~h}$. Ethyl acetate was added to the reaction mixture as a solvent. The prepared polymer was filtered and washed by water to remove the catalyst. The excess water and ethyl acetate was distilled by vacuum distillation to obtain product of approximately $100 \%$ solid content.

\subsubsection{Preparation of polymeric dispersant 4 (PD4)}

PD4 was prepared by ring opening of epoxidized castor oil (ECO) where ECO was mixed with Jeffamine M-2005 in a round bottom flask in the presence of zinc chloride as a catalyst and at temperature $60-70^{\circ} \mathrm{C}$ for $4 \mathrm{~h}$. Ethyl acetate was added to the reaction mixture as a solvent. The prepared polymer was purified by filtration of solid catalyst .The excess ethyl acetate was distilled by vacuum distillation to obtain product of approximately $100 \%$ solid content.

\subsection{Characterization}

\subsubsection{Analytical methods}

\subsubsection{Acid value}

Acid value was determined according to DIN EN ISO 660 (Animal and vegetable fats and oils-determination of acid value and acidity). 


\subsubsection{Iodine value}

Iodine value was determined according to DIN EN ISO 3961 (Animal and vegetable fats and oils-determination of iodine value).

\subsubsection{FTIR analysis}

FTIR spectra were conducted using Bruker FTIR analyzer; ALPHA-Platinum FT-IR Spectrometer with ATR Platinum-Diamond sampling module from 4000 to $400 \mathrm{~cm}^{-1}$.

\subsubsection{Molecular weights determination}

The molecular weights were determined using gel permeation chromatography (GPC) Agilent model 1515 pump system equipped with 1260 infinity refractive index detector and using tetra hydro furan (THF) as eluent, operating with a flow rate of $1.00 \mathrm{~mL} / \mathrm{min}$ at $35^{\circ} \mathrm{C}$. Column PL-gel $3 \mathrm{~lm}$ Mixed E $3007.5 \mathrm{~mm}$ covering a molecular weight range of 600$400,000 \mathrm{mg} / \mathrm{g}$ was used and calibrated using polystyrene standards.

\subsubsection{Water content}

Water content was determined using the Karl Fischer Titrator model Metrohm 870 Titrino plus according to (DIN EN ISO 8534).

\subsubsection{Solubility in common solvents}

The test was performed for the prepared polymeric dispersant in which a 50:50 solution was prepared from the polymer and common solvents are ethyl acetate, ethanol, isopropanol and toluene.

\subsubsection{Ink characterization}

The formulated ink was tested using the following techniques:

\subsubsection{Printed film thickness}

The printing ink was formulated according to the formulation given in Table 1. Then it was applied on polypropylene film (thickness $25 \mu$ ) using hand coater. The film thickness was measured using KAFER micrometer and was found to be $3 \mu$ for all ink samples.

Table 1: Formulation of printing ink

\begin{tabular}{|c|c|}
\hline Component & Weight \% \\
\hline Nitrocellulose varnish & $30 \mathrm{gm}$ \\
\hline Pigment Cyan 15:3 & $12 \mathrm{gm}$ \\
\hline Plasticizer & $3.5 \mathrm{gm}$ \\
\hline Polymeric dispersant (as100\% solid) & $1.5 \mathrm{gm}$ \\
\hline Ketonic resin & $5 \mathrm{gm}$ \\
\hline Ethanol & $15 \mathrm{gm}$ \\
\hline Ethyl acetate & $33 \mathrm{gm}$ \\
\hline Total weight & $\mathbf{1 0 0} \mathbf{~ g m}$ \\
\hline
\end{tabular}




\subsubsection{Curling}

The curling of the polypropylene printed ink film was carried out according to (ASTM D4825-97).

\subsubsection{Adhesion}

Adhesion was measured according to (ASTM D2252-03) and examined visually for the detached ink from the printed film.

\subsubsection{Stability test}

Stability test of ink was performed according to (ASTM D 1849-95).

\subsubsection{X-rite measurements (Relative color strength- $\Delta E-T r a n s p a r e n c y)$}

Printing ink strength, lightness and shade were measured using EXACT-PANTONE Xrite spectrophotometer, where; $\Delta \mathrm{E}$ represents the differences between samples and standard in these three parameters lightness (1), red/green axis (a), yellow/blue axis (b).

\subsubsection{Gloss}

The gloss of the printed film was measured on the printed polypropylene film using BIUGED BGD $514\left(60^{\circ}\right)$ gloss meter.

\section{Results and discussion}

\subsection{Fatty acid composition of oils}

Approximately fatty acid distribution of soybean and castor oil is shown in Table 2.

Table 2: Fatty acid distribution of soybean oil and castor oil

\begin{tabular}{|c|c|c|c|c|c|c|c|}
\hline Fatty acid \% & Palmitic & Stearic & Oleic & Linoleic & Linolenic & Ricinoleic & other \\
\hline Soybean & 11 & 4 & 26 & 52 & 7 & - & - \\
\hline Castor & 1 & 1 & 3 & 4.2 & 0.3 & 89.5 & 1 \\
\hline
\end{tabular}

\subsection{Acid value and iodine value}

The characteristics features of oils are shown in Table 3

Table 3: Characterization of used oils

\begin{tabular}{|c|c|c|}
\hline Oil & $\begin{array}{c}\text { Acid value } \\
\mathbf{m g ~ N a O H / g}\end{array}$ & $\begin{array}{c}\text { Iodine value } \\
\text { gm } \mathbf{I}_{\mathbf{2}} / \mathbf{1 0 0 g m}\end{array}$ \\
\hline Soybean oil & 1.42 & 125.8 \\
\hline Castor oil & 1.98 & 84.6 \\
\hline
\end{tabular}

\subsection{Properties of polymeric dispersant}

The characteristics feature of polymeric dispersants are shown in Table 4.

Table 4: Characteristic features of polymeric dispersants

\begin{tabular}{|c|c|c|c|c|c|c|}
\hline & \multicolumn{4}{|c|}{ Solubility in solvents } & \multirow{2}{*}{ Solid content } & \multirow{2}{*}{ Water content } \\
\hline & Ethanol & Ethyl acetate & Toluene & Isopropanol & & \\
\hline PD1 & $S$ & $S$ & $\mathrm{~S}$ & $\mathrm{~S}$ & $98.6 \%$ & $0.12 \%$ \\
\hline PD2 & $S$ & $S$ & $\mathrm{~S}$ & $\mathrm{~S}$ & $96.5 \%$ & $0.20 \%$ \\
\hline PD3 & $S$ & $S$ & $S$ & $S$ & $99.1 \%$ & $0.16 \%$ \\
\hline PD4 & $\mathrm{S}$ & $\mathrm{S}$ & $\mathrm{S}$ & $\mathrm{S}$ & $99.8 \%$ & $0.11 \%$ \\
\hline
\end{tabular}




\subsection{Fourier Transform Infrared (FT-IR) analysis}

The FT-IR spectra in Figure 5 show the disappearance of double bond group peak at $3009 \mathrm{~cm}^{-1}$ demonstrated the conversion of double bond of oils to the epoxy group. Formation of epoxy group in the spectrum of fingerprint region was indicated by the peaks at 843 and $824 \mathrm{~cm}^{-1}$. The $\mathrm{C}=\mathrm{O}$ ester peak of the triglyceride appears at $1743 \mathrm{~cm}^{-1}$ and the hydroxyl peak at $3460 \mathrm{~cm}^{-1}$.

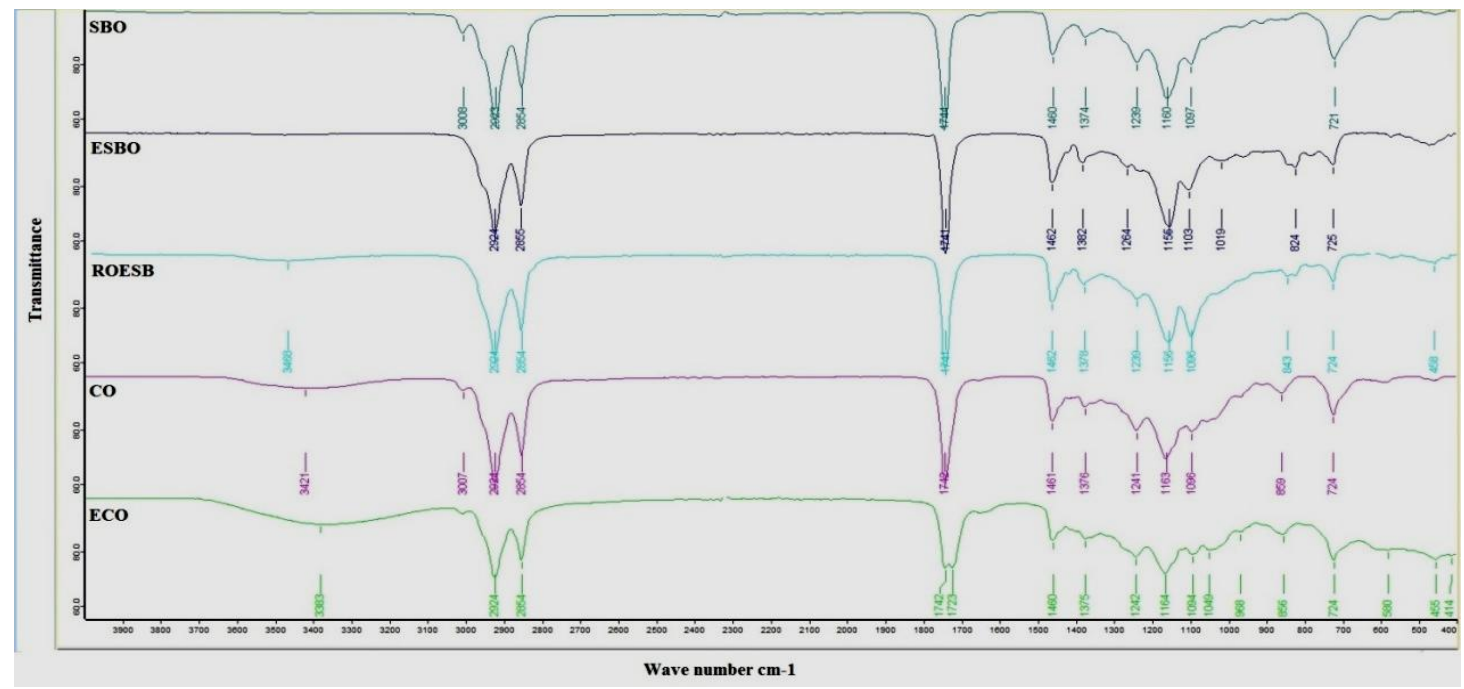

Figure 5: The FTIR spectra of soybean oil (SBO), castor oil (CO), epoxidized soybean oil (ESBO), partially ring opened epoxidized soybean oil (ROESBO) and epoxidized castor oil (ECO).

The FTIR spectra of polymeric dispersants in Figure 6 show characteristic bands of Jeffamine ${ }^{\circ}$ M2005: at $2875 \mathrm{~cm}^{-1}$ and $2970 \mathrm{~cm}^{-1}$ (for the stretching vibrations of $\mathrm{CH}_{2}$ and $\mathrm{CH}_{3}$ groups, respectively), at $1450 \mathrm{~cm}^{-1}$ and $1370 \mathrm{~cm}^{-1}$ (for the bending vibrations of $\mathrm{CH}_{2}$ and $\mathrm{CH}_{3}$ groups, respectively), at $1090 \mathrm{~cm}^{-1}$ (for the ether $\mathrm{C}-\mathrm{O}-\mathrm{C}$ band of Jeffamine ${ }^{\circledR}$ M2005), at $1743 \mathrm{~cm}^{-1}$ (for $\mathrm{C}=\mathrm{O}$ ester peak of the triglyceride) and $3458 \mathrm{~cm}^{-1}$ (for the hydroxyl group, $\mathrm{OH})$.

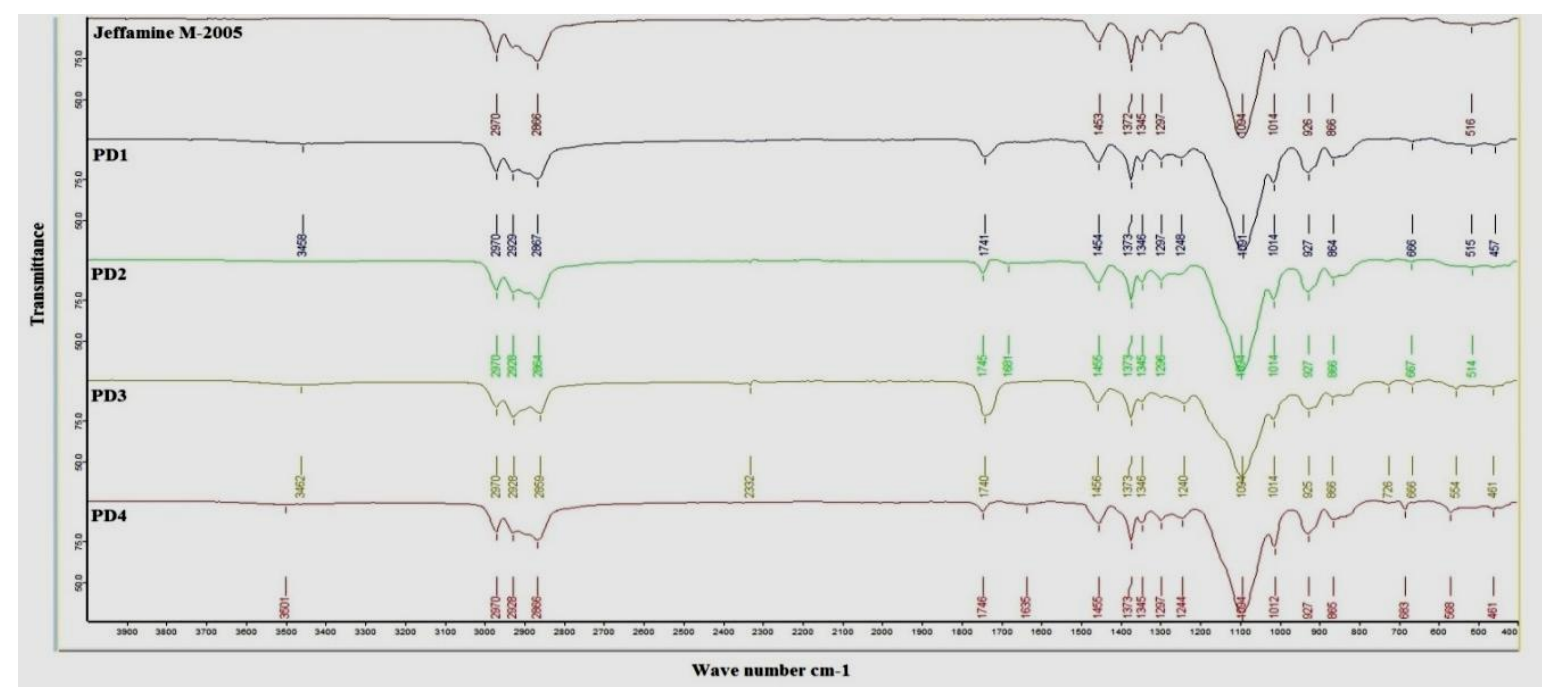

Figure 6: The FTIR spectra of polymeric dispersant PD1, PD2, PD3, PD4 and Jeffamine M-2005. 


\subsubsection{Molecular weight}

Number average molecular weight $(\mathrm{Mn})$ and molecular weight polydispersity index (PDI) were affected by the ring opening of oxirane groups. Table 5 represents the GPC results.

Table 5: The gel permeation chromatography (GPC) data of polymeric dispersant

\begin{tabular}{|c|c|c|c|}
\hline Sample & Mn & Mw & PDI \\
\hline STD & $2.3867 \mathrm{e}^{3}$ & $4.9785 \mathrm{e}^{3}$ & 2.08 \\
\hline Soybean oil & $1.2673 \mathrm{e}^{3}$ & $1.3394 \mathrm{e}^{3}$ & 1.05 \\
\hline Castor oil & $1.3698 \mathrm{e}^{3}$ & $1.4543 \mathrm{e}^{3}$ & 1.06 \\
\hline Jeffamine & $2.5189 \mathrm{e}^{3}$ & $3.1357 \mathrm{e}^{3}$ & 1.24 \\
\hline PPG2000 & $2.6125 \mathrm{e}^{3}$ & $2.9186 \mathrm{e}^{3}$ & 1.11 \\
\hline PD1 & $4.1034 \mathrm{e}^{3}$ & $5.1535 \mathrm{e}^{3}$ & 1.25 \\
\hline PD2 & $4.2816 \mathrm{e}^{3}$ & $5.4831 \mathrm{e}^{3}$ & 1.28 \\
\hline PD3 & $3.7386 \mathrm{e}^{3}$ & $5.1733 \mathrm{e}^{3}$ & 1.38 \\
\hline PD4 & $3.2449 \mathrm{e}^{3}$ & $3.7023 \mathrm{e}^{3}$ & 1.14 \\
\hline
\end{tabular}

From Table 5, the result of GPC refers that at least one molecule of jeffamine react with one epoxide group.

\subsection{Printed film properties}

\subsubsection{Printing ink formulation, application}

The printing ink was formulated according to the formulation given in Table 1. All ink formulations were milled on shaker after addition of glass beads, and then they were applied on polypropylene film using hand coater.

The properties of printing inks related to standard ink with the prepared polymeric dispersant are summarized in Table $\mathbf{6}$ before and after the stability test.

Table 6: Properties of printing ink

\begin{tabular}{|c|c|c|c|c|c|c|c|c|c|c|}
\hline \multirow[t]{3}{*}{ PD } & \multicolumn{2}{|c|}{ Mechanical } & \multicolumn{8}{|c|}{ Optical properties } \\
\hline & \multirow{2}{*}{ Curling } & \multirow{2}{*}{ Adhesion } & \multicolumn{2}{|c|}{ Transparency\% } & \multicolumn{2}{|c|}{$\Delta \mathrm{S} \%$} & \multicolumn{2}{|c|}{$\Delta \mathrm{E} \%$} & \multicolumn{2}{|c|}{ Gloss \% } \\
\hline & & & $\mathrm{B}^{*}$ & $\mathrm{~A}^{*}$ & $\mathrm{~B}^{*}$ & $\mathrm{~A}^{*}$ & $\mathrm{~B}^{*}$ & $\mathrm{~A}^{*}$ & $\mathrm{~B} *$ & $A^{*}$ \\
\hline STD & No Curling & A & \multicolumn{8}{|c|}{ Used as a Standard for X-rite, Gloss meter } \\
\hline PD1 & No Curling & $\mathrm{A}$ & 98.3 & 86.4 & 94.1 & 91.9 & 1.12 & 2.5 & 96.7 & 96.5 \\
\hline PD2 & No Curling & A & 99 & 97.8 & 94 & 92.1 & 2 & 2.8 & 100 & 95.8 \\
\hline PD3 & No Curling & $\mathrm{B}$ & 98.3 & 96.4 & 92.78 & 83.8 & 2.5 & 3.8 & 91 & 87.8 \\
\hline PD4 & No Curling & $\mathrm{A}$ & 109.6 & 96.8 & 92.29 & 88.1 & 1.2 & 1.9 & 100 & 98.2 \\
\hline
\end{tabular}

$A^{*}$ : After stability; B*: Before stability.

The data reported in Table 6 indicated that polymeric dispersants were prepared successfully by the partial substitution of petroleum polymers with vegetables oil derivative. Castor oil and soybean oil gave very comparable mechanical and optical properties. 


\section{Conclusions}

The present study demonstrated, the preparation of polymeric dispersants based on castor oil and soybean oil via epoxidation of oils followed by ring opening with different ring opening agents such as methanol, polypropylene glycol, and polyether amine. The prepared polymer was used in ink formulation to evaluate its efficiency. The results obtained were evaluated compared with commercial polymeric dispersant. It indicates that all prepared dispersants show high optical, mechanical properties and high stability for ink before and after stability test.

The polymeric dispersant 2 (PD2) and polymeric dispersant 4 (PD4) gave the best results (optical and mechanical) among the prepared polymer.

\section{References}

Abdullah BM, Salimon J, Epoxidation of vegetable oils and fatty acids: Catalysts, methods and advantages. J. Appl. Sci. 10:1545-1553 (2010).

Adekunle KF, A Review of Vegetable Oil-Based Polymers : Synthesis and Applications, Open J. Polym. Chem. 5:34-40 (2015).

Alaa MA, Yusoh K, Hasany SF, Synthesis and characterization of polyurethane organoclay nanocomposites based on renewable castor oil polyols. Polym. Bull. 72:1-17 (2014).

Aug J, Leroy F, Lithium Trifluoromethanesulfonate-catalysed Aminolysis of Oxiranes. Tetrahedron Lett. 37:7715-7716 (1996).

Balo F, Castor oil-based building materials reinforced with fly ash, clay, expanded perlite and pumice powder. Ceram. - Silikaty. 55:280-293 (2011).

Biswas A, Manthiram A, Sharma BK, Willett JL, Erhan SZ, Cheng HN, Soybean oil as a renewable feedstock for nitrogen-containing derivatives, Energy Environ. Sci. 1:1-7 (2008).

Can E, Wool RP, Küsefoglu S, Soybean and castor oil based monomers: Synthesis and copolymerization with styrene. J. Appl. Polym. Sci. 102:2433-2447 (2006).

Clarke JB, Rheology modifiers and pigment dispersants. In: Surface Application of Paper Chemicals, J. Brander et al. (Eds.), pp109-110 (1997).

Curini M, Epifano F, Marcotullio MC, Rosati O, Zirconium Sulfophenyl Phosphonate as a Heterogeneous Catalyst in the Preparation of $\beta$-Amino Alcohols from Epoxides. Eur. J. Org. Chem, 4149-4152 (2001). 
Dinda S, Patwardhan AV, Goud VV, Pradhan NC, Epoxidation of cottonseed oil by aqueous hydrogen peroxide catalysed by liquid inorganic acids. Bioresour. Technol. 99:3737-3744 (2008).

Eren T, Küsefoğlu SH Synthesis and Polymerization of the Bromoacrylated Plant Oil Triglycerides to Rigid, Flame-Retardant Polymers. J. Appl. Polym. Sci., 91: 2700-2710 (2004).

Eren T, Küsefoğlu SH, Wool R Polymerization of maleic anhydride-modified plant oils with polyols. J. Appl. Polym. Sci. 90:197-202 (2003).

Holser RA, Transesterification of Epoxidized Soybean Oil to Prepare Epoxy Methyl Esters. Ind. Crops. Prod. 27:130-132 (2008).

Kim HM, Kim HR, Hou CT, Kim BS, Biodegradable photo-crosslinked thin polymer networks based on vegetable oil hydroxy fatty acids. J. Am. Oil Chem. Soc. 87:14511459 (2010).

Kuo K, Peng Y, Chiu W, Don T, A Novel Dispersant for Preparation of High Loading Pigment. J. Polym. Sci. A Polym. Chem. 46:6185-6197 (2008).

Liu W, Chen T, Xie T, Qiu R, Soybean oil-based thermosets with N-vinyl-2-pyrrolidone as crosslinking agent for hemp fiber composites. Compos. Part A Appl. Sci. Manuf. 82:17 (2016).

Lokhande GP, Jagtap RN, Design and synthesis of polymeric dispersant for waterborne paint by atom transfer radical polymerization. Des. Monomers Polym. 19: 256270 (2016).

Lubguban AA, Tu Y, Lozada ZR, Hsieh FH, Suppes GJ, Functionalization via Glycerol Transesterification of Polymerized Soybean Oil . J. Appl. Polym. Sci. 112:1927 (2009).

Meyer P, Techaphattana N, Manundawee S, Sangkeaw S, Junlakan W, Tongurai C ,Epoxidation of Soybean Oil and Jatropha Oil. Thammasat Int. J. Sc. Tech. 13 Special edition (2008).

Milchert E, Smagowicz A, Lewandowski G, Optimization of the epoxidation of rapeseed oil with peracetic acid. Org. Process Res. Dev. 14:1094-1101 (2010).

Mohammad M, Nikje A, Abedinifar F, Idris A ,Epoxidized Soybean Oil Ring Opening Reaction under MW Irradiation. Arch. Appl. Sci. Res. 3:383-388 (2011).

Mushtaq M, Tan IM, Nadeem M, Devi C, Lee SYC, Sagir M, Rashid U, Epoxidation of methyl esters derived from Jatropha oil: An optimization study. Grasas Y Aceites. 64:103-114 (2013). 
Nsib F, Ayed N, Chevalier Y ,Selection of dispersants for the dispersion of carbon black in organic medium. Prog. Org. Coatings 55:303-310 (2006).

Pal L, Fleming P, The Study of Ink Pigment Dispersion Parameters. Rev. Lit. Arts Am. 2:61-70 (2006).

Philippe C, Milcent T, Crousse B, Non Lewis acid catalysed epoxide ring opening with amino acid esters. Organic \& Biomolecular Chemistry 10:2026-2028 (2009).

Reuter E, Silber S, Psiorz C, Use of new block copolymeric dispersing agents for waterborne paints - theoretical and practical aspects, Prog. Org. Coatings. 37:161-167 (1999).

Saithai P, Lecomte J, Dubreucq E, Tanrattanakul V, Effects of different epoxidation methods of soybean oil on the characteristics of acrylated epoxidized soybean oil-co-poly (methyl methacrylate) copolymer. Express Polym. Lett.7: 910-924 (2013).

Salih N, Salimon J, Yousif E, Synthesis of oleic acid based esters as potential basestock for biolubricant production, Turkish J. Eng. Environ. Sci. 35:115-123 (2011).

Saremi K, Tabarsa T, SHakeri A, Babanalbandi A, Epoxidation of soybean oil. 3 (9):4254-4258 (2012).

Schofield JD, Extending the boundaries of dispersant technology. Prog. Org. Coatings. 45: 249-257 (2002).

Schofield JD, Calbo LJ ,Handbook of Coating Additives, Vol. 2, Marcel Decker, New York, pp 71-104 (1992).

Spinelli HJ, Polymeric Dispersants in Ink Jet Technology. Adv. Mater. 10: 1215-1218 (1998).

Stropoli SJ, Elrod MJ, Assessing the Potential for the Reactions of Epoxides with Amines on Secondary Organic Aerosol Particles. J. Phys. Chem. A. 119:10181-10189 (2015).

Sudha GS, Mohanty S, Nayak SK, Synthesis and Optimization of Epoxidized Castor Oil in the Presence of a Sulphonated Polystyrene Type Cation Exchange Resin Catalyst. Int. J. Chem. Eng. 2:112-114 (2015).

Takahashi T, Hirayama KI, Teramoto N, Shibata M, Biocomposites Composed of Epoxidized Soybean Oil Cured with Terpene-Based Acid Anhydride and Cellulose Fibers. J. Appl. Polym. Sci, 108:1596-1602 (2008).

Tryznowska ZZ Additives for Ink Manufacture. In: Printing on Polymer Fundamentals and Applications, Elsevier, pp 57-66 (2016). 
Vlček T, Petrović ZS, Optimization of the chemoenzymatic epoxidation of soybean oil .J. Am. Oil Chem. Soc. 83:247-252 (2006).

Wang J, Feng Y, Xie J, Li G, Li X ,Dispersion of Phthalocyanine Green G in Nonaqueous Medium Using Hyperdispersants and Application in E-Ink. J. Dispers. Sci. Technol. 27: 975-981(2006).

Zhan G, Zhao L, Hu S, Gan W, Yu Y, Tang X, A novel biobased resin-epoxidized soybean oil modified cyanate ester. Polym. Eng. Sci, 48:1322-1328 (2008).

Zhu J, Chandrashekhara K, Flanigan V, Kapila S, manufacturing and mechanical properties of soy-based composites using pultrusion. Composites Part A 35:95-101 (2004).

\section{ملخص البحث باللغة العربية}

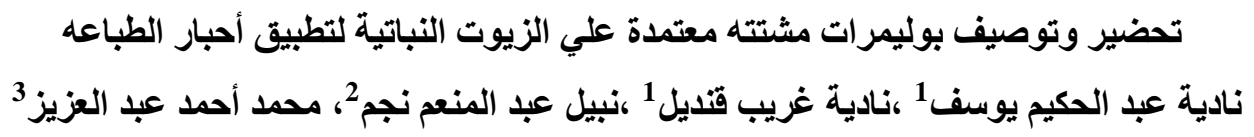

1 قسم الكيمياء ،كلية البنات ،جامعه عين شمس ،القاهرة ،مصر

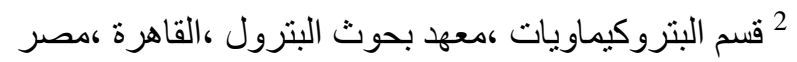

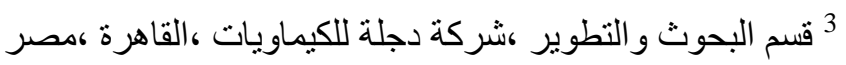

$$
\text { الزيوت التباتية مثل زيت الصويا وزيت الخروع حيث تتميز هذه البوليمرات التي تستخدم كمثتتات للمخضبات والتي تعتمد في تحضيرها علي بتو افترها ورخص ثمنها. يتم تحضير }
$$

البوليمرعن طريق عملية الأكسدة للروابط الثنائية بجزيئات الزيت ثم اضافة البوليمر ليقوم بفتح الحلقة الثلاثية ومثال علي ذلك استخدام البولي بروبيلين جليكول. ثم استخدام البوليمرات التي تم تحضيرها في تركيبات للاحبار كمثتت

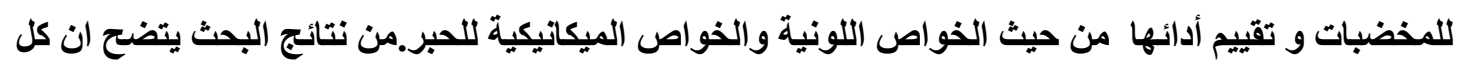
البوليمرات التي تم تحضيرها لها أداء جيا جدا مقارنة بالبوليمرات المستخدمة صناعيا من حيث الخواص اللونية 
